\title{
Pesquisa biomédica e produção de imunobiológicos em São Paulo: um duelo entre o público e o privado
} Luiz Antonio Teixeira*

\section{Resumo}

Este texto se originou de uma apresentação que proferi no seminário "Médicine, science et santé dans les rapports Brésil-France: présent, passe et futur" realizado pela Fiocruz e pelo Instituto Pasteur em 2005, como um dos eventos do Ano Brasil na França. Embora seja uma reflexão bastante preliminar, acredito que sua publicação seja interessante à medida que possibilite pensar de forma integrada a trajetória das instituições biomédicas de São Paulo.

Discutiremos alguns aspectos da trajetória institucional dos Institutos Pasteur de São Paulo e Butantan, abordando seu contexto de criação, seu desenvolvimento e as crises por que passaram ainda na primeira metade do século XX. Iniciaremos apresentando, de forma comparativa, a trajetória das duas instituições, ressaltando a grande ampliação de suas atividades nas primeiras décadas do século XX. Em seguida observaremos o desenvolvimento das instituições privadas voltadas para a fabricação de produtos biológicos

\footnotetext{
* Pesquisador e Professor do Programa de Pós-graduação em História das Ciências e da Saúde da Casa de Oswaldo Cruz - Fiocruz Teixeira@fiocruz.br
} 
e outros medicamentos e analisaremos comparativamente o desenvolvimento dessas últimas simultaneamente às dificuldades vividas pelas duas primeiras. Por fim, nos voltaremos para o processo de consolidação institucional do Pasteur e do Butantan no contexto mais recente de expansão das ações profiláticas de saúde pública.

\section{O surgimento dos institutos de pesquisa biomédica}

O surgimento dos institutos de pesquisa biomédica no Brasil ocorre no período que se estende entre a última década do século XIX e os primeiros anos do século XX. Em 1888, antes mesmo da criação do Instituto Pasteur de Paris, foi inaugurado pelo Imperador Pedro II o Instituto Pasteur do Rio de Janeiro. No entanto, essa instituição, como diversas outras em nossa terra, não chegou a se consolidar pela prática de atividades científicas, se limitando a simples utilização da técnica de produção da vacina e tratamento anti-rábico desenvolvidos por Pasteur. Tal qual o Pasteur do Rio de Janeiro, outros laboratórios foram criados com objetivo de efetuar pesquisas no campo da microbiologia, no entanto, grande parte deles não logrou sucesso em sua trajetória, se extinguindo em poucos anos, ou se transformando em meros espaços de elaborações de exames de rotina para os clínicos ou para a saúde pública.

São Paulo seria o primeiro estado brasileiro a criar instituições de pesquisa bacteriológica mais perenes. Embora vivenciasse um período de crescimento populacional e socioeconômico, relacionado ao grande desenvolvimento da agricultura cafeeira baseada em mão de obra imigrante, o estado sofria com constantes epidemias de febre amarela e varíola. Para transformar esse quadro, ainda no final do Império, o estado paulista começou a dar maior atenção à saúde pública financiando a Inspetoria de Higiene do Estado com verbas da imigração. Com a proclamação da Republica (1989) e a adoção do sistema federativo, as questões de saúde pública no Brasil se tornaram competência dos governos estaduais. Para enfrentar essa nova conjuntura, o estado de São Paulo criou uma forte estrutura de saúde pública que visava reunir e ampliar os poucos serviços então existen- 
tes. O Serviço Sanitário do Estado de São Paulo começou a ser implantado em 1892, tendo como seu principal sustentáculo, uma rede de laboratórios de saúde pública voltados prioritariamente para o diagnóstico de doenças epidêmicas, elaboração de imunobiológicos e produção de insumos para as desinfecções ${ }^{1}$.

O principal deles foi o Instituto Bacteriológico - veio a chamarse Instituto Adolpho Lutz, em homenagem ao seu mais célebre pesquisador - que era responsável pelo diagnóstico das epidemias que surgiam no Estado. Em seus primeiros anos de existência Lutz e seus dois auxiliares elaboraram importantes trabalhos científicos, como as experiências de ratificação da teoria havanesa da febre amarela e um conjunto de trabalhos sobre a febre tifóide que lograram diferenciar o diagnóstico dessas doenças das febres genéricas que ocorriam na cidade de São Paulo. Resolvido o enigma das principais doenças epidêmicas que afetavam o Estado, o Bacteriológico passou a se dedicar principalmente aos exames bacteriológicos para a saúde pública, não chegando a se consolidar como um grande centro produtor de conhecimentos científicos originais.

Em 1899, sob o impacto de uma epidemia de peste bubônica na cidade portuária de Santos foi criado o Instituto Butantan. A preocupação não era sem sentido, pois Santos era o principal porto do país, onde desembarcavam os imigrantes que vinham mover a lavoura cafeeira paulista e eram enviadas as sacas de café que garantiam a maior parte de nossas divisas. Além disso, temia-se que a doença pudesse chegar aos maiores centros urbanos do país, as cidades de São Paulo e o Rio de janeiro, então capital federal ${ }^{2}$.

1 A rede se compunha pelos institutos Vacinogênico e Bacteriológico e pelos laboratórios Farmacêutico e de Análises Químicas e Bromatológicas. Sobre o Serviço Sanitário de São Paulo ver Ribeiro, 1993.

2 Em virtude deste mesmo problema sanitário foi criado na então capital federal o Instituto Soroterápico Federal que, a partir de 1908, em virtude do grande reconhecimento obtido por Oswaldo Cruz pelo saneamento da capital federal, passou chamar-se Instituto Oswaldo Cruz. Ao final da primeira década do século XX, O Instituto Oswaldo Cruz era uma instituição ímpar no cenário científico brasileiro, pois contava com um grande número de técnicos, laboratórios equipados e rendas infinitamente maiores do que qualquer instituição congênere no país. No campo científico, seu modelo, baseado na pesquisa 
Em 1904, surgiria ainda o Instituto Pasteur de São Paulo, instituição privada de caráter filantrópico que teve grande produtividade científica até 1915, quando foi encampado pelo Estado e transformado num posto de vacinação antirábica. A maior importância deste instituto reside no fato de, diferentemente de várias outras instituições que surgiram no país com essa mesma denominação, o Pasteur de São Paulo foi o único que, como seu inspirador francês, se voltou para a pesquisa científica, não se limitando somente à produção da vacina e ao tratamento anti-rábico. A partir de 1906, sob a direção do italiano Antônio Carini, o Pasteur de São Paulo produziu um grande número de trabalhos científicos em medicina humana, muitos deles apresentados à Sociedade de Medicina e Cirurgia de São Paulo. O Instituto também foi ativo no campo da veterinária, onde elaborou vários trabalhos para os criadores paulistas (Teixeira, 1995).

Neste trabalho nos deteremos somente na trajetória do Butantan e do Pasteur de São Paulo. Estas duas instituições, embora tenham sido criadas sob perspectivas totalmente diferenciadas e seguido caminhos também distintos, trazem em comum o fato de terem vivenciado fortemente os problemas relacionados ao desenvolvimentos de um setor privado de produção de imunobiológicos e outros produtos de uso em saúde pública e em veterinária até então monopolizados por instituições públicas e filantrópicas. Por outro lado, a escolha dessas instituições nos possibilita discutir o alguns aspectos mais recentes da produção de imunobiológicos no país e analisar o processo de revalorização desses institutos a parir da segunda metade do século XX e, em especial no último quartel do referido século.

\section{Sobre o Instituto Butantan}

A história do Instituto Butantan, na primeira metade do século XX, já foi várias vezes contada por historiadores da medicina bra-

produção de vacinas e especialização médica, rendia importantes frutos, contabilizados principalmente em descobertas científicas de aplicação em saúde humana e veterinária e na formação de pessoal capacitado nos novos campos da medicina laboratorial (Benchimol e Teixeira, 1993). 
sileira e mostra uma trajetória de grande desenvolvimento em meio a diversas crises, afinal em pouco mais de cem anos o Instituto se transformou no maior fabricante de produtos biológicos do país e num dos seus maiores centros de pesquisa biomédica. Em estudos anteriores procurei demonstrar que essas crises se relacionaram principalmente às dificuldades oriundas da falta de coesão interna, que acredito ter sido determinada por dois fatores: uma disputa entre os aliados e opositores de Vital Brazil, seu criador e por quase 20 ano único diretor, e uma tensão entre os limites do público e do privado na produção de imunobiológicos e ao direito de aplicação das pesquisas realizadas no Instituto (Teixeira, 2001 e 2005). Senão Vejamos:

O Instituto Butantan foi criado em 1899 como dependência do Instituto Bacteriológico de São Paulo. Para dirigi-lo foi convidado o médico Vital Brazil, que há alguns anos vinha trabalhando com pesquisas para a elaboração de soros antiofídicos. Já no ano seguinte, transformado em instituição autônoma do Serviço Sanitário, passou a ser denominado Instituto Soroterápico de São Paulo, tendo como função oficial o preparo de soros e vacinas contra as doenças epidêmicas que atacavam o Estado. Apesar da especificidade da missão que lhe foi atribuída, o capital científico de seu diretor - já detentor de grande notoriedade em virtude de ter descoberto a especificidade dos soros antiofídicos - possibilitou que o Butantan se voltasse mais fortemente para as pesquisas no campo do ofidismo, sem, contudo deixar de produzir os imunobiológicos demandados pela saúde pública.

Com o passar dos anos o Butantan foi se ampliando e se transformando na base de produção de soros e vacinas do Serviço Sanitário. Seus poucos pesquisadores além de se trabalharem nas atividades de produção, também se voltavam para as pesquisas científicas, principalmente as relacionadas ao ofidismo. Na segunda metade da década de 1910 ocorreriam grandes transformações em sua trajetória. Em 1916 a direção da Saúde Pública paulista passou as mãos do médico baiano Arthur Neiva (1880-1943). Antigo chefe 
de Serviço do Instituto Oswaldo Cruz, no Rio de Janeiro, Arthur Neiva havia feito parte das expedições científicas da instituição que percorreram diversos rincões do país em busca de materiais e objetos de pesquisa ou executando atividades de profilaxia e combate a surtos epidêmicos. O conhecimento sobre as condições sociais e de saúde no interior do país, adquiridos nessas expedições, transformou Neiva num forte defensor do saneamento rural. $\mathrm{Na}$ direção do Serviço Sanitário de São Paulo ele procuraria transformar o modelo de saúde pública paulista concebido no final do século anterior. Sua meta era incorporar à pauta de atividades da saúde pública as regiões do interior do Estado ${ }^{3}$. Para implementar essa diretriz, procurou dar um novo perfil ao Instituto Butantan, tentando transformá-lo na base do Serviço Sanitário para a pesquisa e produção de medicamentos para as endemias que assolavam o interior do Estado. Com esse objetivo, reformou o Instituto ampliando bastante suas atividades. A partir de 1917, o Butantan também passou a ter como atribuições o estudo e cultivo de plantas medicinais, a elaboração de medicamentos destinados à saúde pública e a fiscalização dos soros, vacinas comercializados em São Paulo. Para efetivar a reforma foi dobrado seu plantel de pesquisadores, criadas novas seções, como a de botânica, química e um horto para plantas medicinais e uma planta industrial para a produção de medicamentos contra a ancilostomose e a malária. Além disso, foram criadas as Memórias do Instituto, periódico científico até hoje existente.

Apesar dos esforços, o projeto de ampliação do Butantan não vingou. Ele começou a ruir em 1919, quando Vital Brazil deixou a instituição, junto com vários outros pesquisadores, para montar um instituto privado no Estado do Rio de Janeiro. Sua saída detonou uma grave crise, sendo que a falta de profissionais para dar continuidade às pesquisas e à produção gerou uma drástica redução nas atividades do Instituto.

3 A partir de 1916 Neiva participou ativamente de um movimento em prol do saneamento do interior do país que congregou cientistas, médicos e intelectuais. Sobre o movimento pelo saneamento dos serões ver: Hochman e Lima, 1996. 
É nesse ponto da história do Butantan que as tensões se inauguram. Vital Brazil havia dirigido a instituição desde sua fundação, sendo reconhecido e mitificado pela maior parte de seus pares como seu criador e responsável único pelo seu desenvolvimento. Para esse grupo, sua saída era conseqüência de uma política autoritária que não levava em conta a tradição de pesquisas da instituição, querendo transformá-la numa fábrica de medicamentos. Por outro lado, seu ingresso na iniciativa privada foi duramente criticada por alguns de seus pares, que viam nesse processo uma inaceitável transferência dos conhecimentos adquiridos no setor público para o setor privado. Quem mais perseveraria nessa posição foi o médico Afrânio do Amaral, que o substituiria na direção do Instituto.

$\mathrm{O}$ dissenso aberto pela controvérsia em relação à atitude de Vital Brazil de deixar o Butantan e criar uma instituição privada com fins próximos aos do Instituto fez com que o Butanatan tivesse grande dificuldade na escolha de seus dirigentes, que por algum tempo se sucederam sem, contudo, lograr obter uma maior coesão interna da instituição. Isso não quer dizer que houvesse uma paralisia institucional, pelo contrário. Em meados da década de 1920, o Butantan já se mostrava como uma instituição central na defesa sanitária do Estado de São Paulo. De seus laboratórios brotavam diversas pesquisas, prioritariamente relacionadas ao ofidismo. Em sua linha de produção eram elaborados todos os imunobiológicos utilizados pela saúde pública paulista. Muitos deles eram ainda vendidos a outros estados. São Paulo não podia parar e o Butantan era fundamental para que ele andasse.

Em 1928 o Butantan voltou a ser dirigido por Afrânio do Amaral. Em sua administração o Instituto adquiriu o status de centro de medicina experimental, agora voltado para estudos no campo da medicina humana e dos animais venenosos, e não mais centrado somente na produção de imunobiológicos. Os frutos dessas mudanças começaram a surgir nos anos seguintes quando foi deflagrada de uma política institucional de ampliação das atividades de pesquisa através da contratação de renomados pesquisadores estrangeiros 
que, devido as crescentes tensões na Europa, viram a migrar para São Paulo. Logo o Instituto teve ampliada suas linhas de investigação e a produção de imunizantes.

Mas apesar do grande desenvolvimento institucional, o $\mathrm{Bu}-$ tantan, neste período, convivia com uma forte dissensão interna gerada com a implantação do regime de tempo integral, previsto na reforma de 1931. Essa medida, fortemente defendida por Afrânio, desagradou os que também trabalhavam em laboratórios privados e foram impedidos de continuar a fazê-lo, ou abandonaram o Butantan par dedicar-se somente a esses laboratórios. Além disso, Afrânio havia afastado alguns técnicos acusados de fazer usos de trabalhos desenvolvidos no Instituto em seus laboratórios privados. Em 1936, a crise se agravaria ainda mais, devido à abertura de um inquérito administrativo contra Afrânio do Amaral pelos técnicos que lhes eram antagonistas. Estes o acusavam de improbidade administrativa e responsabilizam-no pela morte de dois pesquisadores que foram infectados nos laboratórios de produção.

No contexto de xenofobia e autoritarismo crescentes, gerados com a implantação de uma ditadura no país em 1937, Afrânio do Amaral foi destituido da direção do Butantan, os pesquisadores estrangeiros foram obrigados a deixarem seus cargos, por serem vistos pelo governo como uma ameaça à segurança nacional e vários inquéritos administrativos impediram o funcionamento de diversos setores. No cômputo geral, várias seções foram fechadas, a pesquisa foi reduzida e também a produção. Só para se ter uma idéia da gravidade do problema, no período que decorre de 1938 a 1944 o Instituto Butantan teve mais de uma dezena de diretores, todos eles administrando a instituição por um curto espaço de tempo. Era a ditadura getulista e suas funestas conseqüências para o Instituto.

Os problemas do Butantan chegariam ao auge em 1947, quando o pesquisador Eduardo Vaz foi convidado para dirigi-lo. Egresso da indústria farmacêutica privada, ele acreditava que a pesquisa só deveria ter lugar num instituto quando fosse a base para a produção, e que o Butantan deveria ter como objetivo central a fabricação 
de produtos para a saúde pública. Para colocar suas diretrizes em ação Vaz obteve do governo estadual uma nova reforma nos estatutos do Butantan, que passaram a limitar suas atividades à preparação de imunobiológicos para a defesa sanitária e aos estudos sobre animais peçonhentos. Em conformidade com essa nova orientação, vários laboratórios foram fechados ou transferidos para outras instituições. De forma semelhante, muitos pesquisadores deixaram o Instituto, ou levaram suas investigações para a Universidade de São Paulo ou para a Escola Paulista de Medicina. Tais diretrizes foram impostas de forma extremamente autoritária, e acabaram por violentar a tradição de pesquisa da instituição, fazendo-a mais uma vez mergulhar em uma crise.

Somente na segunda metade do século XX, o Butantan deixaria de conviver com os conflitos que até então marcaram a sua trajetória. Para isso concorreu o progressivo aumento do consenso sobre o papel da pesquisa e da produção na instituição e o fortalecimento do setor público no campo da produção de imunobiológicos. Nos anos 50, o Brasil vivia um momento de afirmação e da ciência, que passava ser vista como de importância estratégica para o país. Nesse contexto, o Butantan conseguiria consolidar sua vocação de Instituto de medicina experimental. Já o resgate de sua missão de produtor de soros e vacinas para a saúde pública ocorreu a partir da desnacionalização da indústria farmacêutica brasileira e do desinteresse do setor na elaboração de produtos biológicos pouco lucrativos. Nesse contexto, a produção pública voltou a ter papel de destaque.

\section{O Instituto Pasteur de São Paulo}

O Instituto Pasteur de São Paulo foi criado em 1903, como uma instituição privada, filantrópica por um grupo de médicos e beneméritos paulistas liderados pelos médicos Ulysses Paranhos e Bittencourt Rodrigues. Em 18 de fevereiro de 1904 a instituição foi inaugurada oficialmente, no prédio à Avenida Paulista onde se encontra até os dias de hoje. Embora de caráter privado, o Instituto 
sempre sobreviveu às expensas do Estado que durante todo o seu período inicial lhe facultou verbas através das câmaras municipais e estadual.

Seus organizadores imaginaram uma instituição nos moldes de seu congênere francês, que se voltasse para a pesquisa biomédica e para o tratamento antirábico. Com o objetivo de garantir que as investigações do Instituto teriam a mesma qualidade das elaboradas nos centros científicos europeus, a comissão organizadora moveu grandes esforços para contratar pesquisadores estrangeiros para dirigir a instituição. Primeiro foi o médico italiano Ivo Bandi que ficou apenas um mês no cargo. Em 1905, o médico italiano Antonio Carini, veio de um instituto da Suíça ocupar o cargo.

O período de 1906 a 1915 foi bastante profícuo para o Instituto que, sob a direção de Antonio Carini, se transformou numa importante instituição anti-rábica, também voltada para a pesquisa e para atividades de formação de quadros técnicos no campo da microbiologia. Além disso, o Instituto Pasteur dessa época também produzia e comercializava diversos produtos de uso médico e veterinário como vacinas, soros e reagentes para diagnósticos. No campo das pesquisas produziu um grande número de trabalhos científicos em medicina humana, muitos deles apresentados à Sociedade de Medicina e Cirurgia de São Paulo e também foi ativo no campo da veterinária, onde elaborou vários trabalhos para os criadores paulistas. Entre suas investigações destacam-se as pesquisas elaboradas por Carini na região de Binguassu, interior de Santa Catarina, em 1911, que demonstraram a possibilidade de transmissão da raiva pelos morcegos hematófagos ${ }^{4}$.

4 Carini foi convidado para investigar um surto de uma doença desconhecida no gado bovino em uma localidade de Santa Catarina. Lá, observou a existência de morcegos hematófagos e verificou indícios de ataque destes ao gado. Aventou então a hipótese de que a doença que atingia a região era a raiva, e estava sendo transmitida pelo morcego hematófago. De volta ao Instituto Pasteur comprovou sua hipótese em laboratório, no entanto sua teoria somente foi aceita anos mais tarde, quando dois pesquisadores alemães fizeram a mesma constatação (Teixeira, 1995). 
A importância do instituto Pasteur de São Paulo reside no fato de, diferentemente de várias outras instituições que surgiram no país com essa mesma denominação, ele foi o único que, como seu inspirador francês, se voltou para a pesquisa científica, não se limitando somente a produção da vacina e ao tratamento antirábico.

A partir de 1914, com as dificuldades econômicas provenientes do advento da I Guerra Mundial e em virtude do desenvolvimento de instituições estaduais que desempenhavam algumas das funções do instituto - como o Butantan, fabricante de um grande número de produtos biológicos, e a Faculdade de Medicina, responsável pela formação médica, a visibilidade da instituição começou a declinar e, junto com ela, as doações que a mantinham também se reduziram. Logo, o Instituto ingressou em uma forte crise financeira, agravada ainda mais com a progressiva diminuição dos subsídios vindos de diversas municipalidades e principalmente do governo estadual.

Em pouco tempo as rendas auferidas tornaram-se insuficientes para a manutenção do instituto no âmbito privado. Neste período, o governo paulista vinha elaborando estudos para criar uma instituição estatal de combate à raiva, pois assim teria mais controle das ações em relação a doença e ao financiamento para o seu controle. Frente à realidade do Pasteur e seu objetivo, o governo do Estado celebrou um acordo com a direção do Pasteur transferindo-o para o Serviço Sanitário do Estado. Só que com essa mudança as atividades do Instituto ficaram restritas somente à preparação da vacina e atendimento aos vitimados por animais suspeitos. Em 21 de março de 1916 foi efetivada a doação da instituição ao governo paulista, assim terminando a primeira fase do Instituto Pasteur de São Paulo.

Somente em 1918 o Instituto foi reinaugurado como instituição do Estado. Seu prédio foi totalmente reformado, ganhando novas feições. Para dirigi-lo foi convidado o médico Eduardo Rodrigues Alves, que permaneceu trinta anos à frente da instituição. Nesta segunda fase do Instituto Pasteur, as pesquisas científicas se limitaram ao aperfeiçoamento das técnicas de fabricação da vacina, do soro e 
do diagnóstico e tratamento antirábico. No campo da defesa contra a doença, seus diretores se empenham fortemente na normalização da criação doméstica e no combate aos cães vadios; no entanto, somente os poderes municipais poderiam colocar em prática essas atividades e a maioria deles não tinha interesse em transformá-las em prioridade. A partir da década de 1930, a atuação do Instituto nesse campo perde ainda mais sua importância à medida que o Instituto Pinheiros (organização industrial privada criada por antigos pesquisadores do Instituto Butantan) começa a produzir a vacina antirábica e enviá-la para seus vários representantes do interior do Estado, que repassavam aos médicos locais, num processo de descentralização do combate a doença no Estado. Já em seus primeiros anos, o alcance da vacina do Instituto Pinheiros ultrapassava em muito o do Instituto Pasteur de São Paulo. A atuação do Pasteur se restringiria ainda mais na década de 1950 quando a produção dos soros e vacinas antirábicas foi transferida para o Instituto Butantan.

De uma forma muito geral podemos dividir a história do Instituto nos primeiros três quartéis do século XX em duas fases bastante diferenciadas. A primeira, quando o Instituto era uma instituição filantrópica, foi marcada por seu grande desenvolvimento no campo do tratamento antirábico associado à pesquisa, ao ensino e a elaboração de produtos biológicos. $\mathrm{Na}$ segunda fase, já sob o controle do Estado, o Pasteur trilhou períodos de estagnação, tendo sua atuação, na maior parte do tempo, limitada ao diagnóstico e tratamento da raiva, e sofrendo as dificuldades de não conseguir ser ouvido em relação às suas propostas de controle da doença.

\section{Amarrando alguns fios}

Uma rápida observação destas instituições nos deixa entrever um certo padrão em seu desenvolvimento. Ambas tiveram um período de expansão inicial marcante, ajudando a consolidar a medicina experimental no Brasil. Era a época heróica da microbiologia no país. Tal qual Oswaldo Cruz e seu instituto no Rio de Janeiro, o Butantan e o Pasteur de São Paulo em seus primeiros anos foram 
uma importante alavanca na melhoria das condições de saúde no Estado e no desenvolvimento de sua base científica. A partir do final da década de 1910 e, principalmente nos anos 1930, a situação se transformaria em virtude de contínuo crescimento dos laboratórios privados de produção de medicamentos e produtos biológicos que começaram a dividir o espaço com essas instituições.

No âmbito mais geral esse contexto foi marcado pelas transformações que vinham ocorrendo na produção farmacêutica brasileira. Nos primeiros anos do século XX essa produção tinha como bases as boticas e pequenos laboratórios, onde eram fabricados por processos artesanais elixires, vinhos e licores reconstituintes - além de pomadas e produtos de beleza - utilizando principalmente extratos de origem animal e vegetal extraídos de plantas medicinais. A partir da segunda metade da década de 1910, a escassez de produtos farmacêuticos, determinada pelo início da Primeira Guerra, fez com que a indústria farmacêutica nacional se expandisse, implantando novos métodos de produção iniciando a fabricação de produtos de origem estrangeira. À frente desse processo muitas vezes estavam pesquisadores do setor público que aos poucos se transformaram em empreendedores da iniciativa privada no campo da produção de imunobiológicos, opoterápicos e fitoterápicos. Assim, a produção de imunobiológicos que foi, desde seu surgimento no país, monopolizada por instituições públicas passou a também ter como base diversas empresas privadas. Estas, contando com o know-how dos técnicos formados pelas instituições biomédicas já existentes e, muitas vezes, contando com maior agilidade na comercialização de seus produtos, conseguiam destaque numa área até então dominada por instituições públicas. Vejamos alguns exemplos:

Em 1912, alguns pesquisadores do Instituto Pasteur de São Paulo, liderados pelo médico Ulisses Paranhos, fundaram o Laboratório Paulista de Biologia. Aproveitando a experiência anteriormente adquirida, eles passaram a oferecer produtos e serviços semelhantes aos do Instituto Pasteur, ainda fabricados de forma artesanal. Com a incorporação do Instituto Pasteur ao Serviço Sanitário, alguns de 
seus antigos técnicos paulatinamente foram migrando para a nova instituição, que conseguiu refazer o plantel inicial de seus principais pesquisadores. Com as dificuldades de importação de produtos causadas pela Primeira Guerra Mundial, as vendas do Laboratório se ampliaram bastante, sendo que na década de 1920 ele já era uma empresa de grande porte que fabricava centenas de especialidades e exportava medicamentos para vários países latino-americanos. $\mathrm{Na}$ década de 1960, o Laboratório Paulista de Biologia já ocupava o posto de sexto maior laboratório farmacêutico nacional.

Como mencionamos anteriormente, em 1919 Vital Brazil deixou o Butantan - instituição que por quase duas décadas dirigira - e se transferiu para a cidade de Niterói, no Rio de Janeiro, onde fundou o Instituto Vital Brazil, instituição voltada prioritariamente para a produção de soros e outros produtos biológicos. Através de acordos com o governo do Rio de Janeiro, o Instituto obteve algumas vantagens fiscais em troca da obrigação de produzir algumas vacinas para o Estado. Em alguns anos o Instituto Vital Brazil se consolidou como importante instituição fluminense de produção de imunobiológicos e medicamentos, só vindo a entrar em decadência na década de 1950, no contexto mais geral da crise da indústria farmacêutica nacional.

Com um perfil semelhante ao Instituto Vital Brazil, foi criado em 1925 o Instituto Pinheiros. Dirigido por Eduardo Vaz e Mario Augusto Pereira, técnicos vindos dos institutos Butantan e do Vital Brazil, o Pinheiros especializou-se na fabricação de produtos biológicos, como a vacina antirábica, a BCG e os soros antiofídicos, antitetânico e antidiftérico. Estabelecendo uma grande rede de distribuição voltada também para as regiões rurais, o Instituto chegou a suplantar alguns institutos públicos na venda de vacinas e outros produtos de saúde pública para as diversas unidades federativas do país. Em menos de duas décadas, o Pinheiros havia ampliado fortemente suas atividades, se transformando no maior fabricante nacional de produtos biológicos. No final da década de 50 ele situava-se entre as 20 maiores indústrias farmacêuticas do país, mantinha 12 filiais e mais de 1200 funcionários (Ribeiro, 2000). 
Estes laboratórios privados não concorriam diretamente com o setor público, uma vez que a produção desses últimos era distribuída para a saúde pública e suas pesquisas, na maior parte do tempo, custeadas por verbas não relacionadas à comercialização de seus produtos. No entanto, a constante transferência de técnicos das instituições públicas para as privadas e a ampliação do volume de negócios desse mercado agiu como um gerador de instabilidades no processo de desenvolvimento das instituições públicas. O caso do Instituto Pasteur mostra bem esse processo. Embora ele produzisse a vacina e efetuasse o tratamento antirábico em sua sede, a capacidade do Instituto Pinheiros em distribuí-la para a venda em todo o interior do Estado - o produto era vendido aos clínicos, que se responsabilizavam por sua aplicação quando surgiam casos suspeitos ou confirmados - o fazia muito mais importante no que tange à profilaxia da doença. Em relação ao Butantan, a transferência de seus técnicos para a iniciativa privada e a utilização de pesquisas por eles realizadas em seus empreendimentos, foi uma constante causa de conflitos internos. A inexistência de normas institucionais que regessem essas questões possibilitava o surgimento de diversas interpretações em relação a esses pontos, normalmente colocando em oposição os que se ligavam a novas instituições e os que os apoiavam e os profissionais dedicados unicamente ao Butantan.

A despeito do papel das instituições comerciais no processo de crise dos institutos públicos ou filantrópicos, é imperioso afirmar é que o desenvolvimento da indústria farmacêutica moderna no Brasil foi estimulada pelo investimento estatal em instituições públicas de pesquisa. Essas, além de cumprirem importante papel na defesa sanitária e no desenvolvimento científico do país, contribuíram para a formação de cientistas e pesquisadores que muitas vezes vieram a criar ou potencializar o desenvolvimento da parcela privada do setor (Benchimol e Teixeira, 1993 e Ribeiro, 2000).

Observar a relação do desenvolvimento das empresas comerciais de produção farmacêutica com as crises das instituições biomédicas nascidas no início do século XX não representa dizer que 
somente sua atuação foi responsável por este processo. Tal afirmação seria um forte reducionismo, pois não leva em conta as grandes transformações internas e externas ao campo científico que se desenrolam nesse período. No campo técnico-científico, por exemplo, os desafios surgidos a partir do desenvolvimento da farmacologia e da química a partir da década de 1930, não conseguiram ser ultrapassados pelos pesquisadores nacionais, com a mesma facilidade que os provenientes da era dos micróbios. No que tange à atuação desses institutos no campo da produção de conhecimentos científicos, vemos que cada vez mais elas passaram a dividir o espaço com a Faculdade de Medicina - implantada em 1913 - e com outros institutos, como o Biológico, criado em 1927. No que concerne ao interesse público pela suas atividades, o cenário também foi se transformando. O Instituto Pasteur, a partir de sua integração ao Serviço Sanitário (1916), foi caracterizado como um posto de vacinação, passando a contar com pouquíssimas verbas para a sua manutenção. Já o Butantan, desde a primeira década do século XX, era reconhecido como a principal instituição de pesquisa biomédica do Estado. Mas, apesar desse reconhecimento lhe proporcionar a obtenção de verbas crescentes para suas atividades, estas muitas vezes foram reduzidas em virtude de problemas econômicos e políticos vividos pelo Estado. Nos primeiros anos da década de 1930, por exemplo, o Instituto passou por grandes dificuldades em virtude dos problemas financeiros do Estado, decorrentes da implantação do governo de Getúlio Vargas.

Resumindo nosso argumento, podemos afirmar que as dificuldades vividas pelo Instituto Pasteur e pelo Butantan, a partir do final da década de 1910 e, principalmente da década seguinte se relacionaram, embora de forma não exclusiva, ao desenvolvimento da indústria farmacêutica nacional. Desenvolvimento esse possibilitado pela ação dessas instituições na formação de pessoal qualificado nos diversos campos da medicina experimental. 


\section{De volta para o futuro}

O resgate do papel de produtor de soros e vacinas para a saúde pública pelo Instituto Butantan e de agente central da defesa antirábica pelo Instituto Pasteur ocorreria num período bem mais contemporâneo. Num contexto de desnacionalização da indústria farmacêutica brasileira e de desinteresse do setor privado na elaboração de produtos biológicos pouco lucrativos, a produção pública voltou a ter papel de destaque. Não é por acaso que o marco de criação de um programa integrado de produção de imunizantes no país se vincula a uma crise de desabastecimento de soro antiofídico determinada pela descontinuidade da produção da substância pelo laboratório Sintex do Brasil, multinacional de medicamentos que algum tempo antes havia comprado o Instituto Pinheiros.

Já na década de 1960, a participação do Instituto Butantan nas grandes campanhas de vacinação seria fundamental para o controle de doenças como a difteria, o sarampo e, principalmente, para sucesso da campanha nacional de erradicação da varíola. Na década seguinte, ele se transformaria numa das instituições centrais dos programas federais criados para intensificar o controle de doenças transmissíveis e ampliar a auto-suficiência do país na produção de imunobiológicos. A ação do Butantan nessas iniciativas consolidaria seu papel de instituição central na produção de imunobiológicos para a saúde pública nacional.

Em relação ao Pasteur, o caminho é semelhante: sua forte atuação no programa de controle da raiva, com a implantação das campanhas de vacinação canina e de vigilância sanitárias foi fundamental para o seu restabelecimento como instituição central para o controle da doença no país. Todo esse processo começaria no início da década de 1970, quando o problema do controle da raiva no Estado de São Paulo estava na ordem do dia e o Instituto promoveu um seminário internacional sobre técnicas de controle da raiva (1972). Esse evento teve como uma de suas conseqüências, a criação de uma Comissão Permanente de Controle da Raiva no Estado. Em 1975, frente a uma recomendação da Organização Panamericana 
de Saúde e do Ministério da Saúde, o Estado de São Paulo começou a implantar um programa de controle da raiva - antes mesmo do Ministério da Saúde começar a implementar ações nesse sentido. A partir de então, com a implementação da vacinação canina, ocorreu uma importante queda na incidência de casos de raiva humana no Estado. O número de casos na década de 1970, que era de cerca de 20 por ano, em média, na década de 1990 foi de um caso a cada dois anos. Recentemente o Pasteur vem colhendo os frutos de seus esforços na ampliação de suas atividades em relação à raiva, se caracterizando como laboratório de referência nacional para a raiva e coordenando os sistemas de controle e avaliação dos laboratórios de raiva dos Ministérios da Saúde da Agricultura, Pecuária e Abastecimento. Hoje, Pasteur e Butantan estão unindo esforços para viabilizar a produção de uma vacina contra a raiva produzida com tecnologia 100\% nacional. Elaborada no Instituto Butantan e testada no Instituto Pasteur de São Paulo, o novo produto passará a ser fabricado em escala industrial ainda esse ano.

\section{Bibliografia}

100 anos de butantan [COORDENAÇÃO GERAL E REVISÃO DE TEXTOS HENrique Moisés Canter; texto Antonio Virgilio da Silva]. São Paulo: Gabarito de Marketing Editorial, 2000.

ALMEIDA, Marta de. República dos invisíveis: Emílio Ribas, microbiologia, e saúde pública em São Paulo 1898-1917. Bragança Paulista: editora da Universidade São Francisco, 2003.

BENCHIMOL, Jaime e TEIXEIRA, Luiz. Cobras, Lagartos e Outros Bichos: uma história comparada dos Institutos Oswaldo Cruz e Butantan. Rio de Janeiro, UFRJ/Fiocruz, 1993.

BRAZIL, Vital. Memória histórica do Instituto de Butantan. São Paulo, Elvino Pocai, 1941.

HENRIQUES, Sebastião Baeta. O Instituto Butantan: um ensaio sobre a necessidade de reforma de nossas instituicoes cientificas. Ciência e Cultura. São Paulo, 35: 2, pp::151-7, fev.1983. HOCHMAN, Gilberto e Lima, Nísia Trindade. Condenado pela 
raça, absolvido pela medicina: o Brasil redescoberto pelo movimento sanitarista da primeira república. in: Maio, Marcos e Ventura, Ricardo (orgs.) Raça, Ciência e Sociedade. Rio de Janeiro, Editora Fiocruz/CCBB, 1996, pp. 23-40.

RANGEL Filho. A evolução da indústria farmacêutica no Brasil. Rio de Janeiro, 1956 e

JACOB FRENKEL et all. Tecnologia e competição na indústria farmacêutica brasileira. FINEP/Centro de Estudos e Pesquisas/Grupo de Estudos Sobre Progresso Técnico e Estrutura Industrial, 1978. RIBEIRO, Maria Alice Rosa. História sem fim... um inventário da saúde pública: São Paulo 1880-1930. São Paulo, Unesp, 1993. RIBEIRO, Maria Alice Rosa. Saúde Pública e as Empresas Químico-farmacêuticas. História, Ciências, Saúde-Manguinhos. Vol VII, número 3, 2000, p.607-26.

TEIXEIRA, Luiz Antonio. Ciência e Saúde na Terra dos Bandeirantes: a trajetória do Instituto Pasteur de São Paulo (1903-1916). Rio de Janeiro, Editora da Fiocruz, 1995.

TEIXEIRA, Luiz Antonio, SANDOVAL, Maria Regina Cardoso e TAKAOKA, Neide Yumie. Instituto Pasteur de São Paulo: cem anos de combate à raiva. História, Ciências, Saúde - Manguinhos, Dez 2004, vol.11, no.3, p.751-766.

TEIXEIRA, Luiz Antonio. Repensando a História do Instituto Butantan. In: Dantes, Maria Amélia. Espaços da ciência no Brasil 1880-1930. Rio de Janeiro : Editora Fiocruz, 2001, p.159-184.

TEIXEIRA, Luiz Antonio. Sobre as ciências biomédicas e a saúde pública em São Paulo: a trajetória do Instituto Butantan entre as décadas de 1920 e 1950. Trabalho apresentado no $10^{\circ}$ Seminário Nacional de História da Ciência e da Tecnologia. Belo Horizonte: outubro de 2005. 